\section{GPCRs' grand plans}

\section{By Stephen Parmley, Senior Writer}

In a move to expand tenfold the number of known 3D structures of the highly druggable class of GPCRs, Amgen Inc., Ono Pharmaceutical Co. Ltd. and Sanofi have teamed up with three academic organizations to create the GPCR Consortium - a precompetitive alliance to build an open-source repository of GPCR structures. The consortium could fill a hole left by the termination of the NIH-backed Protein Structure Initiative that until March constituted the main public effort to characterize GPCR structures.

Raymond Stevens-who started the consortium-told SciBX in late November that Novo Nordisk A/S will also join the group. $\mathrm{He}$ expects to sign up another pharma before year end, and he said that the consortium hopes to reach a total of eight industry members.

The academic centers involved-the iHuman Institute at ShanghaiTech University, the Shanghai Institute of Materia Medica and the University of Southern California-will conduct the research on GPCR structures and make the results and supporting data available in the public domain. Financial terms for the consortium were not disclosed.

Stevens is founding director of the iHuman Institute and provost professor of biological sciences and chemistry at the University of Southern California. He is also founder of Receptos Inc. and RuiYi Inc.

The goal is to elucidate the $3 \mathrm{D}$ structures of a large number of GPCRs and generate high-resolution pictures that can be used to explore how the receptors work and aid the design of new compounds. The consortium's initial focus will be on diabetes, cancer and mental disorders based on the industry members' input. But, according to Stevens, there is no limit on therapeutic areas, and new consortium members may have different interests.

Stevens said that with 8 companies on board, the consortium believes it will be able to study at least 200 GPCRs.

Michael Hanson, president of the GPCR Consortium, noted that GPCRs constitute the largest family of proteins in the human body and represent therapeutic targets for about $40 \%$ of marketed drugs. "What is surprising is that these developed drugs really only target a handful of the known family of GPCRs. So there is a vast untapped potential out there," he said. But "at the moment, we only have structures for 26 of the 826 known human GPCRs. There is a lot that we do not know about this family." (See Figure 1, "Solving a family problem.")

Hanson is the former director of structural biology at Receptos.

He said that industry members will provide the consortium with libraries of their chemical compounds, many of which have fallen by the wayside for pharmaceutical or safety reasons. He added that the compounds are great tools for binding receptors and stabilizing them for crystallization and might be useful for bootstrapping structures to develop new drugs.

"Having their help in accessing and generating compounds that are going to bind to the receptors and analyzing the data associated with that binding event is probably the most important aspect of what pharma is bringing to the collaboration," he said.

\section{Lessons learned}

Stevens told SciBX that a major stimulus for the new collaboration was the termination of funding for the Protein Structure Initiative (PSI) by the NIH's National Institute of General Medical Sciences earlier this year. According to an NIH press release, the initiative was discontinued after an external review committee concluded that, despite the gains made since PSI was founded in 2000, the resources, products and results were "underutilized by the broader scientific community."

PSI was originally formed to develop and use high throughput screening systems to solve $3 \mathrm{D}$ atomic-level structures of proteins and make them easily obtainable by the scientific community. The program involved multicenter collaborative studies and produced more than 6,300 protein structures and 400 technologies and methods to streamline the process of structure determination.

Stevens was the principal investigator from The Scripps Research Institute who formed the GPCR Network, a collaborative program funded by PSI to understand GPCR structure and function. He told SciBX that the GPCR structures obtained in the PSI program were viewed as useful but the PSI program was controversial because it was less hypothesis-driven research than the National Institute of General Medical Sciences is currently funding.

He added that for some of the leading academic groups in the field of GPCR structural biology research, the only solution to the cut in PSI funding was to work more closely with industry. By allowing the pharmas to select the targets and collaborate on the science, the consortium hopes to generate data that is more therapeutically useful, he told SciBX.

In putting together the GPCR Consortium, Stevens used the setup of the Structural Genomics Consortium (SGC) as a template with assistance from Aled Edwards, director and CEO of the SGC.

"That model worked really well, particularly for kinases and epigenetics," said Stevens. "Before, labs were solving structures of a few kinases here and there, but the SGC did it in an organized fashion and did an incredible job of opening up the kinase knowledge base." 
Figure 1. Solving a family problem. The GPCR Consortium aims to solve at least 200 unknown structures of GPCRs.

The GPCR superfamily contains 826 members, identified based on sequence similarity of their hallmark 7 transmembrane domains. Structures of 16 GPCRs have already been solved by the GPCR Network (black labels), a division of the NIH-backed Protein Structure Initiative that was terminated in March. Another 10 structures have been solved by other groups, 9 of which are depicted in the dendrogram (gray labels).

GPCRs are divided into five major families: rhodopsin, secretin, adhesion, glutamate and frizzled/taste receptor type 2 (TAS2R; T2R).

Receptors with solved structures in the dendrogram include: adenosine $A_{2 A}$ receptor (ADORA $A_{2 A}$ ), adrenergic receptor $\beta 1$ (ADRB1), ADRB2, CC chemokine receptor 5 (CCR5; CD195), muscarinic acetylcholine receptor M2 (CHRM2; HM2), CHRM3 (HM3), corticotropin-releasing factor receptor 1 (CRHR1; CRFR1), CXC chemokine receptor 1 (CXCR1), CXCR4 (NPY3R), dopamine D3 receptor (DRD3), glucagon receptor (GCGR), metabotropic glutamate receptor subtype 1 (mGluR1; GRM1), histamine $\mathrm{H} 1$ receptor $(\mathrm{HRH} 1)$, serotonin $\left(5-\mathrm{HT}_{1 \mathrm{~B}}\right)$ receptor $(\mathrm{HTR} 1 \mathrm{~B})$, $\mathrm{HTR} 2 \mathrm{~B}$, neurotensin receptor 1 (NTSR1), opioid receptor $\delta 1$ (OPRD1; DOR), $\kappa$-opioid receptor (OPRK1; KOR), opiate receptor-like 1 (OPRL1), $\mu$-opioid receptor (OPRM1; MOR), protease-activated receptor 1 (PAR1), purinergic receptor P2Y G protein-coupled 12 (P2RY12; P2Y12), rhodopsin (RHO; OPN2), smoothened (SMO), sphingosine 1-phosphate receptor 1 (S1PR1; S1P1; EDG1).

Not shown: free fatty acid receptor 1 (FFAR1; GPR40). (Figure adapted from Figure 1 in ref. 2.)

The SGC is a public-private partnership founded in 2004 to determine protein structures that operates out of the University of Oxford and University of Toronto. Results are placed in the Protein Data Bank, which is the primary public source of protein structures. ${ }^{1}$ The GPCR Consortium will also deposit its data in the Protein Data Bank.

Like the SGC, the GPCR Consortium will rely on international collaboration between academic centers that have different strengths and skill sets.

Stevens said, "In terms of novel technologies, in China we will be doing a lot of the in vitro stability screening and signaling assays, and in the U.S. we have access to a new technology called the free electron laser that is able to use much smaller crystals." He also noted that the technology to obtain protein structures has advanced significantly in the last decade, which has lowered the cost and shortened the time it takes to generate structural data.

Hanson added that acquiring the data is just the first step. Industry funding would also be used for organizing and sharing the data so that it can be used more effectively by the pharma partners and the larger biomedical community, he said.
The importance of data management was a lesson learned from the genomics field, which also dealt with vast amounts of data, he said. "It's very analogous to the Human Genome Project, where academia had their effort and industry had their effort," which led to a lot of expense, inefficiency and a cottage industry of small labs engaged in redundant efforts.

"What we are trying to do is take it a step further and evolve, so instead of competing we are working together to collect this information," Stevens said.

"There are a lot of GPCR data being generated, including but not limited to structural data, novel signaling pathways, allosteric modulation and polypharmacology," he said. "We are developing solutions to integrate access and ultimately utilize all of this data to accelerate the process of drug discovery."

Parmley, S. SciBX 7(46); doi:10.1038/scibx.2014.1337

Published online Dec. 4, 2014

\section{REFERENCES}

1. Cain, C. SciBX 4(20); doi:10.1038/scibx.2011.562

2. Katritch, V. et al. Annu. Rev. Pharmacol. Toxicol. 53, 531-556 (2013) 


\section{ANALYSIS}

COMPANIES AND INSTITUTIONS MENTIONED

Amgen Inc. (NASDAQ:AMGN), Thousand Oaks, Calif.

GPCR Consortium, Los Angeles, Calif.

National Institute of General Medical Sciences, Bethesda, Md.

National Institutes of Health, Bethesda, Md.

Novo Nordisk A/S (CSE:NVO; NYSE:NVO), Bagsvaerd, Denmark

Ono Pharmaceutical Co. Ltd. (Tokyo:4528), Osaka, Japan

Receptos Inc. (NASDAQ:RCPT), San Diego, Calif.

RuiYi Inc., La Jolla, Calif.
Sanofi (Euronext:SAN; NYSE:SNY), Paris, France The Scripps Research Institute, La Jolla, Calif.

Shanghai Institute of Materia Medica, Shanghai, China ShanghaiTech University, Shanghai, China

Structural Genomics Consortium, Oxford, U.K.

University of Oxford, Oxford, U.K.

University of Southern California, Los Angeles, Calif.

University of Toronto, Toronto, Ontario, Canada 